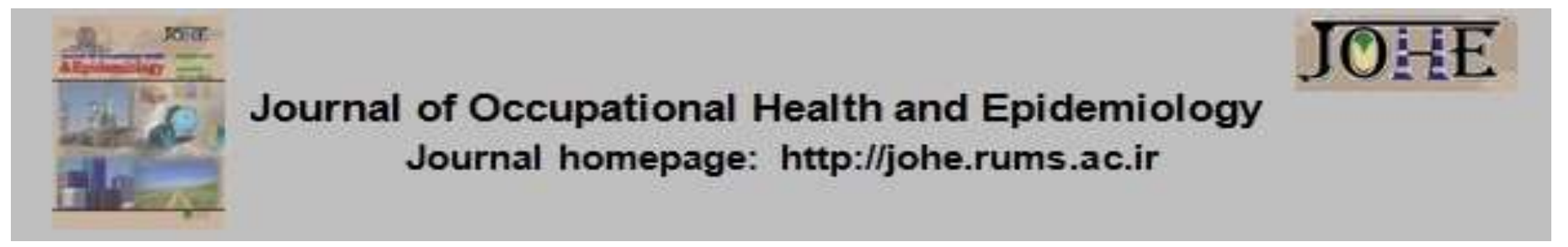

\title{
The Association between Noise Annoyance and General Health among Iranian Nurses at Tabriz Pediatric Hospital
}

\author{
Mehran Eivazzadeh ${ }^{1}$, Akbar Gholampour ${ }^{2,3^{*}}$, Mohammad Asghari Jafarabadi ${ }^{4,5}$, Gholamreza Moradi ${ }^{6}$ \\ 1-MSc in Environmental Health Engineering, Health and Environment Research Center, Tabriz University of Medical Sciences, Tabriz, \\ Iran. \\ 2- Associate Prof., Health and Environment Research Center, Tabriz University of Medical Sciences, Tabriz, Iran. \\ 3- Associate Prof., Dept. of Environmental Health Engineering, Faculty of Health, Tabriz University of Medical Sciences, Tabriz, Iran. \\ 4- Associate Prof., Road Traffic Injury Research Center, Tabriz University of Medical Sciences, Tabriz, Iran. \\ 5- Associate Prof., Dept. of Statistics and Epidemiology, Faculty of Health, Tabriz University of Medical Sciences, Tabriz, Iran. \\ 6- Assistant Prof., Dept. of Occupational Health Engineering, Faculty of Health, Tabriz University of Medical Sciences, Tabriz, Iran.
}

$$
\begin{aligned}
& \text { Citation: Eivazzadeh M, Gholampour A, Asghari Jafarabadi M, Moradi Gh. The Association } \\
& \text { between Noise Annoyance and General Health among Iranian Nurses at Tabriz Pediatric } \\
& \text { Hospital. JOHE } 2019 ; 8(4): 190-8 .
\end{aligned}
$$

Article Info

* Corresponding author:

Akbar Gholampour,

E-mail:

gholampoura@tbzmed.ac.ir

\section{Article history}

Received: Jul 2019

Accepted: Feb 2020

10.29252/johe.8.4.190

Print ISSN: 2251-8096 Online ISSN: 2252-0902

Peer review under Occupational Health and Epidemiology

\begin{abstract}
Background: This study aimed to measure the sound level and assess the association between noise annoyance and general health in Iranian nurses at Tabriz Pediatric Hospital in neonatal, infectious, internal, NICU, and emergency care wards.

Materials and Methods: The noise level was measured continuously according to ISO9612. The general health questionnaire-28, the noise annoyance scale based on ISO15666, and demographic characteristics were the questionnaires used in this study. The study was conducted at Tabriz specialty and subspecialty Hospital for children, which includes different care wards and admits many patients to the hospital.

Results: The highest 24-hour mean noise level (dBA) was measured in the emergency $(69.65 \pm 1.68)$ ward. The highest mean noise level during the morning, afternoon, and night shifts belonged to the emergency ward at $69.53 \pm 0.27,69.30 \pm 0.39$, and $69.85 \pm 0.43$, respectively. According to the results, the association between the equivalent sound exposure level and noise annoyance was significant. The highest mean score of the total GHQ (39.78 \pm 12.01$)$ was obtained in the emergency ward, and the lowest mean score (30.20 \pm 7.15$)$ was obtained in the neonatal ward. The rassociation between the total scale of GHQ-28 and GHQ-28 subscales was significantly positive in all wards.

Conclusion: The mean of the LAeq (dBA), in different wards of the studied hospital, was higher than the levels suggested by the US-EPA, the WHO, the AAP, and the national standard. Accordingly, since the mentioned wards play a vital role in treatment procedures, effective management-technical noise reduction measures are required to be adopted in these wards.
\end{abstract}

Keywords: Noise; Health; Hospital, Pediatrics

\section{Introduction}

Noise is defined as an unwanted sound with a close association with the psychological concept of annoyance. It is considered a public and complex work-related problem in all regions of the world (1). Annoyance is the unpleasant effect of noise disturbance in individuals and groups, which is rooted in a variety of responses moderated by the personal and social features of individuals. Research shows that the subjective annoyance of the sound increases upon raising the sound level. However, at low sound levels, other factors determine whether annoyance occurs $(2,3)$. Noise exerts psychological and physiological effects on humans (4). Some of the adverse 
effects of noise on humans include temporary and permanent hearing loss, hypertension, cardiac arrhythmia, annoyance and stress, sleep disorders, effects on the immune system, as well as impacts on behavior and mental health in individuals $(5,6)$.

Hospitals as institutions providing healthcare services are affected by different sources of noise pollutions, which impose negative impacts on the health and comfort of patients and personnel (7). Staff-patient conversations, telephones, alarms, overhead fluorescent lights, paging systems, televisions, heating and cooling systems, noisegenerating beds, ventilators, medical equipment, the running of sink faucets, the opening and closing of doors, as well as air-conditioning systems are a few examples of noise sources at hospitals $(7,8)$. Numerous studies conducted by the World Health Organization (WHO) imply that the noise level has increased continuously at hospitals since 1960. Since hospitals are supposed to be a safe place for patients and staff, the effects of high levels of noise on patients and staff are among the most serious concerns (9).

Sound levels at hospitals should not exceed $45 \mathrm{~dB}$ in the daytime and $35 \mathrm{~dB}$ at night, according to the standard of the United States Environmental Protection Agency (US-EPA) (10). In the same vein, the WHO suggests that the average noise level should not exceed 35 dBA (A-weighted decibels) in the rooms where patients are treated or observed, and no more than $30 \mathrm{dBA}$ in the wards (11). The American Academy of Pediatrics (AAP) suggests that the sound level should not exceed $45 \mathrm{~dB}$ in the daytime and $35 \mathrm{~dB}$ at night; in addition, the hourly sound level should not exceed $50 \mathrm{~dB}$ in $10 \%$ of the daytime (Ln10), nor should the sound level exceed a 1-sec maximum level (Lmax) of $65 \mathrm{~dB}$ (12). According to the national standard of Iran, the allowed sound limit inside hospitals in the daytime from 7 a.m. to 10 p.m. should equal 45 $\mathrm{dBA}$, and at night from 10 p.m. to 7 a.m., it should equal $35 \mathrm{dBA}$ (13). Several studies show that the sound level at many hospitals is usually higher than those mentioned in these recommendations $(5,14)$.

The association between the nurses' heart rate and noise was examined by Kinstler et al (2015), who considered the impact of noise on nurses in pediatric intensive care units. The results of this study showed that the increase in noise was not associated with stress, but there was a significant correlation between the increase in noise and the increase in the heart rate, implying that noise could be accompanied by adverse health effects (15). In the same context, the results of the study by Christensen et al (2005) showed that noise could exert a negative impact on the performance of ICU nurses (4). The study by Juang et al (2010) demonstrated that noise pollution, either directly or indirectly, could affect the subjective perception of noise as well as the emotions and bodily processes of medical care staff (16).

Some researchers have investigated the health impact of noise pollution, the risk of noise exposure, and its related disorders, yet to the best of the authors' knowledge, there are currently few published studies on the association between noise annoyance and mental health effects among nurses.

Therefore, to better determine authorized sound levels in different hospital wards (neonatal, infectious, internal, NICU, and emergency care wards) and given the lack of relevant studies in this field, the association between noise annoyance and the general health of nurses in different care units of Tabriz Pediatric Hospital was assessed with sound level measurements performed. The data were analyzed using SPSS 24.0.

\section{Materials and Methods}

Tabriz Pediatric Hospital (Iran), an educational hospital affiliated to Tabriz University of Medical Sciences, was selected for this study in the autumn of 2018. The study was conducted in Tabriz specialty and subspecialty Hospital for children, which includes different care wards and admits many patients. It was selected for this study, for it has specialized units, a large number of patients, the availability of hightech medical equipment, a large number of staff, and the high level of activities of nursing teams at the hospital. Nurses were selected as the study population because of their large number in the care wards.

A cross-sectional observational study was conducted to assess noise levels and the association between sound levels and health features in five different specialized pediatric care wards. The studied wards included neonatal, infectious, internal, NICU (neonatal intensive care ward), and emergency care wards. The primary reason for conducting the study in the mentioned units was the large number of patients and nurses in the units. The levels of noise in the studied wards were taken into account.

In this study, the internal ward with 30 beds and 26 nurses, the NICU ward with 22 beds and 47 nurses, the infectious ward with 40 beds and 20 nurses, the neonatal ward with 23 beds and 21 nurses, and the emergency ward with 40 beds and 38 nurses were investigated. From each studied care ward, 10 nurses with rotating shifts (morning, afternoon, and evening) were selected and 
included in the study. Hospitals are suitable research settings because they enable researchers to divide staff members in homogeneous exposure groups (HEGs). Sample size " $n$ " was selected to ensure (at a $95 \%$ level of probability) the presence of at least one worker in the top $20 \%$ of the population exposed in forming the homogeneous exposure group (HEG). This method splits workers into groups so that the levels of exposure to noise could be considered similarly. In total, 50 nurses were observed in the studied care wards.

Sound levels were measured using two TES-1358 sound level meters. The measuring stations were selected according to ISO 9612:2009. For this purpose, three locations, including the nurse station, ward interiors, and patient rooms were selected in different mentioned wards of the hospital. Sound measurements were carried out in different locations at the height of 1.5 and $1 \mathrm{~m}$ from the earth in the nurse station and patient rooms, respectively. The Leq was measured using a calibrated sound level meter (Model TES-1358). Based on the standard measurement method, the Leq (15min) was considered for noise measurement. Measurement stations for noise measurement in the three wards included the entrance to the ward, the nursing station, and the patient room.

In each station, the LAeq (Equivalent A-weighted Sound Level) was measured in 18 different days throughout 24 hours of the day in the autumn of 2018. For this purpose, the instrument was adjusted in $15 \mathrm{~min}$, so we had 296 data for one station in 24 hours. The average of the data was used as the unit data. To include diversities, measurement days were scattered throughout an entire week, except for holidays. It should be noted that to confirm the accuracy of the obtained data, the measuring device was calibrated every day using the supplied calibration device at $94 \mathrm{~dB}$ and at the frequency of $1000 \mathrm{~Hz}$ (accurate by $\pm 0.1 \mathrm{~dB}$ ) before and after the use.

The general health questionnaire-28 (GHQ-28), the noise annoyance scale (NAS), and the demographic characteristics questionnaire were used in this study $(17,18)$. Noise annoyance was determined using the 100-point NAS questionnaire based on ISO 15666. This questionnaire was used to qualitatively assess individual sensitivity to noise. On this scale, based on the obtained scores, annoyance was categorized into one to five groups, including 'not annoyed', 'slightly annoyed', 'rather annoyed', 'annoyed', and 'very annoyed' (Fig. 1). (18)

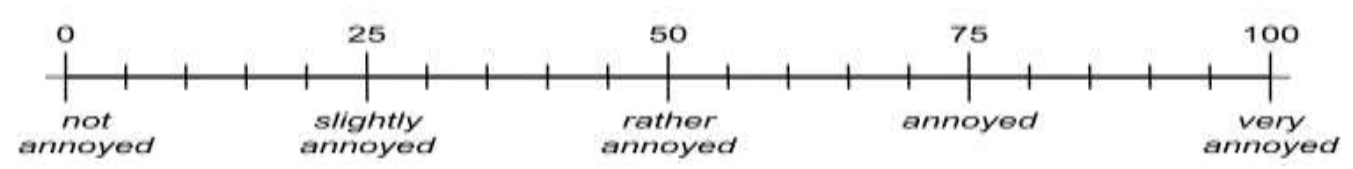

Fig. 1. A 100-point noise annoyance scale (NAS)

The GHQ-28 scale was used to assess general health. The validity and reliability of the GHQ-28 test have been confirmed in most of the past studies (19). Making use of factor analysis, the GHQ-28 questionnaire had four subscales with 7 items in each case, including somatic symptoms (items 1-7), anxiety/insomnia (items 8-14), social dysfunction (items 15-21), and severe depression (items 22-28). Each item was accompanied by four possible responses of 1: not at all, 2: not more than usual, 3: rather more than usual, and 4: much more than usual. Different scoring methods were possible, which could affect the total score. The Likert's scoring method with response scores between 0 and $3(0,1,2$, and 3$)$ was used in this study. In total, the scores ranged from 0 to 84 . Higher scores indicated a greater probability of psychiatric distress, and the total score of 23/24 was the threshold for the presence of distress (17, 19).

The data of sound level measurements at different stations together with the extracted information from the questionnaires were entered into SPSS 24.0. Descriptive statistics were applied to the results of noise, noise annoyance, and general health. A one-way ANOVA was carried out to identify the statistically significant differences of the demographic characteristics and noise annoyance, as well as the association between each of the general health questionnaire subscales among different wards of the hospital. In addition, this test was done to determine sound levels in different wards on different working shifts, i.e. morning, afternoon, and night.

The Pearson's correlation coefficient was determined to examine the association of the general health questionnaire subscales with sound levels and noise annoyance scales. The association between sound levels and noise annoyance as well as the association between GHQ-28 subscales and the total scale were examined using the Pearson's correlation analysis. In addition, the differences and correlations were 
considered significant at the $p$-value of less than 0.05. The data were analyzed using SPSS 24.0.

\section{Results}

Table 1 illustrates the 24-hour mean of the LAeq (dBA) in different wards of the studied hospital. The highest 24-hour mean of the LAeq was determined for the emergency, internal, infectious, neonatal, and NICU wards, respectively. The results of comparing the LAeq values among different wards showed that the values were significantly different, except between neonatal and NICU wards, neonatal and infectious wards, as well as internal and infectious wards ( $p$-value $<0.05$ ). In addition, the highest mean differences of the LAeq were obtained between emergency and NICU wards ( $p$-value $<0.05$ and mean difference=9.18).

Table 1. Mean values of the LAeq in different wards of the studied hospital

\begin{tabular}{cccccc}
\hline \multirow{2}{*}{ Ward } & Neonatal & NICU & Internal & Infectious & Emergency \\
\cline { 2 - 6 } & Mean \pm SD & Mean \pm SD & Mean \pm SD & Mean \pm SD & Mean \pm SD \\
\hline LAeq $_{\text {ave(dB) }}$ & $62.35 \pm 0.88$ & $60.48 \pm 1.93$ & $66.35 \pm 2.40$ & $64.25 \pm 2.09$ & $69.65 \pm 1.68$ \\
\hline
\end{tabular}

Table 2 presents the statistical analysis results of the sound level in various wards during morning, afternoon, and night shifts. The results indicate that the highest mean sound level belonged to the emergency care ward $(69.53 \pm 0.27,69.30 \pm 0.39$, and $69.85 \pm 0.43$ for morning, afternoon, and night shifts, respectively). Furthermore, the lowest mean sound level was related to NICU $(59.98 \pm 0.96$, $61.53 \pm 0.29$, and $60.15 \pm 0.57$ for morning, afternoon, and night shifts, respectively). The results of the one-way ANOVA revealed that sound levels significantly differed among the shifts in all wards (P-value $<0.05)$.

Table 2. Statistical analysis of the sound level (dBA) on different shifts

\begin{tabular}{ccccccc}
\hline \multicolumn{2}{c}{ Shift } & NICU & Neonatal & Infectious & Internal & Emergency \\
\hline \multirow{2}{*}{ Morning } & Mean \pm SD & $59.98 \pm 0.96$ & $61.83 \pm 1.66$ & $63.17 \pm 0.66$ & $66.55 \pm 1.96$ & $69.53 \pm 0.27$ \\
\cline { 2 - 7 } & $\mathbf{9 5 \%}$ Cl & $58.97-60.99$ & $60.09-63.58$ & $62.47-63.86$ & $64.50-68.60$ & $69.25-69.82$ \\
\hline \multirow{2}{*}{ Afternoon } & Mean \pm SD & $61.53 \pm 0.29$ & $63.47 \pm 0.56$ & $65.07 \pm 0.82$ & $67.38 \pm 0.86$ & $69.30 \pm 0.39$ \\
\cline { 2 - 7 } & $\mathbf{9 5 \%}$ Cl & $61.22-61.84$ & $62.88-64.05$ & $64.20-65.93$ & $66.48-68.28$ & $68.89-69.71$ \\
\hline \multirow{2}{*}{ Night } & Mean \pm SD & $60.15 \pm 0.57$ & $61.95 \pm 0.52$ & $64.41 \pm 0.71$ & $65.78 \pm 0.50$ & $69.85 \pm 0.43$ \\
\cline { 2 - 7 } & $\mathbf{9 5 \% ~ C l ~}$ & $59.80-60.50$ & $61.62-62.28$ & $63.96-64.87$ & $65.46-66.10$ & $69.58-70.12$ \\
\hline
\end{tabular}

Fig. 2 depicts a summary of the data achieved for 24-hour measurements by averaging the levels found in all five units. According to the results, the highest and most fluctuating noise values achieved in the daytime were related to the period between 10:00 a.m. and 05:00 p.m. in all wards excluding the emergency ward. In contrast, the lowest noise values, i.e. the quiet period, were achieved between 05:30 p.m. and 10:30 p.m., which was nevertheless only $2-5 \mathrm{~dB}$ quieter than the noisiest time of the day.

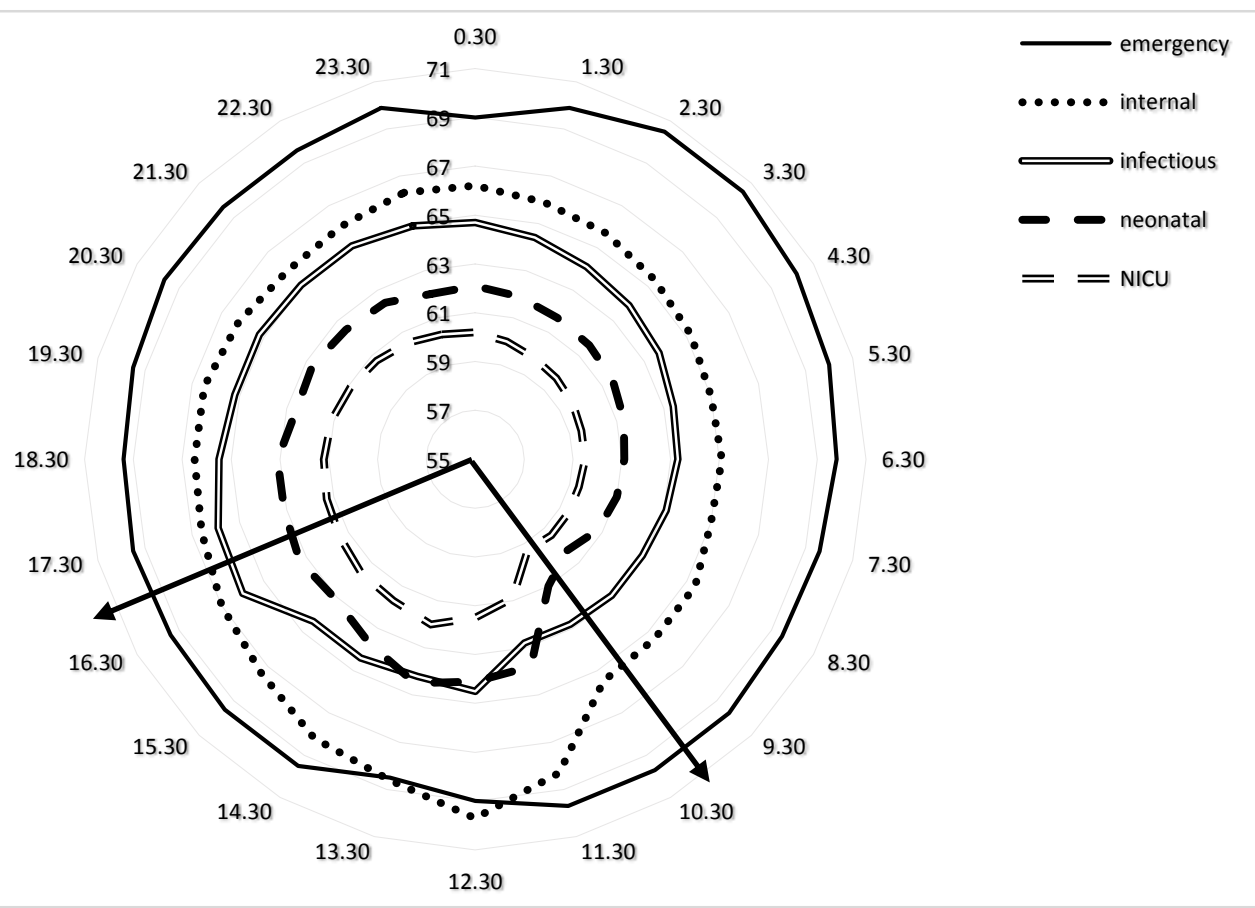

Fig. 2. A-weighted equivalent sound pressure levels measured in various wards according to the time of the day 
According to Fig. 2, there has been less than $5 \mathrm{~dB}$ of variations and fluctuations from the lowest to the highest sound pressure level in all wards. The highest variation in the sound pressure level (about $5 \mathrm{~dB}$ ) was related to the internal ward. In contrast, the emergency ward had the lowest variation (about $1 \mathrm{~dB}$ ) in the sound pressure level during the 24 hours of the daytime and was noisy all day long.

Table 3 shows the results from the statistical analysis of the staff's demographic characteristics in different wards of the studied hospital. According to the obtained results, the highest mean of the staff's age and work experience was related to the NICU and emergency wards, respectively. Furthermore, the highest percentage of the married and single individuals was related to the $\mathrm{NICU}$ and internal wards, respectively. Based on the ANOVA analysis, there was no significant difference ( $p$-value $>0.05$ ) among the demographic characteristics, such as the mean of work experience, marital status, age, daily working hours, weekly working hours, the number of people living at home, and the number of children among the staff in different wards.

Table 3. Mean values of demographic characteristics in different wards of the studied hospital $(\mathrm{N}=50)$.

\begin{tabular}{|c|c|c|c|c|c|c|c|c|}
\hline \multirow{2}{*}{ Ward } & \multirow{2}{*}{$\begin{array}{c}\text { Mean work } \\
\text { experienc } \\
\text { e (year) }\end{array}$} & \multicolumn{2}{|c|}{ Marital status } & \multirow{2}{*}{$\begin{array}{c}\text { Mean } \\
\text { age }\end{array}$} & \multirow{2}{*}{$\begin{array}{c}\text { Mean } \\
\text { daily } \\
\text { working } \\
\text { hours }\end{array}$} & \multirow{2}{*}{$\begin{array}{c}\text { Mean } \\
\text { weekly } \\
\text { working } \\
\text { hours }\end{array}$} & \multirow{2}{*}{$\begin{array}{c}\text { Mean } \\
\text { number of } \\
\text { people } \\
\text { living at } \\
\text { home }\end{array}$} & \multirow{2}{*}{$\begin{array}{c}\text { Mean } \\
\text { number } \\
\text { of } \\
\text { children }\end{array}$} \\
\hline & & $\begin{array}{c}\text { Married } \\
(\%)\end{array}$ & $\begin{array}{c}\text { Single } \\
(\%)\end{array}$ & & & & & \\
\hline Neonatal & 7.90 & 60 & 40 & 32.00 & 7.80 & 50.20 & 3.70 & 1.50 \\
\hline NICU & 8.10 & 80 & 20 & 33.40 & 7.40 & 53.60 & 3.30 & 1.13 \\
\hline Internal & 6.10 & 40 & 60 & 29.30 & 7.40 & 48.90 & 3.70 & 0.75 \\
\hline Infectious & 6.22 & 77.78 & 22.22 & 29.33 & 7.11 & 49.78 & 3.11 & 0.86 \\
\hline Emergency & 10.44 & 55.56 & 44.44 & 33.11 & 7.44 & 48.33 & 3.44 & 1.40 \\
\hline
\end{tabular}

Table 4 shows the mean and standard deviation of the general health questionnaire subscales (GHQ) for different wards of the studied hospital. The highest mean values of somatic symptoms (10.33 \pm 3.43 ), anxiety/insomnia (10.67 \pm 3.91 ), and severe depression $(9.33 \pm 6.58)$ subscales were obtained for the emergency ward, while the lowest mean values of the same variables were obtained for the neonatal ward. In addition, the highest $(9.80 \pm 3.29)$ and lowest $(6.80 \pm 1.99)$ mean scores of the social dysfunction subscale were obtained for the internal and NICU wards, respectively. Furthermore, the highest and lowest mean score of the total GHQ was obtained for the emergency ward (39.78 $\pm 12.01)$ and the neonatal ward (30.20 \pm 7.15$)$, respectively.

The subscales of the general health questionnaire were surveyed in different wards by a one-way ANOVA. According to the results obtained, somatic symptoms, anxiety/insomnia, and severe depression subscales were not significantly different in different wards of the hospital ( $p$-value $>0.05$ ), while the social dysfunction subscale was significantly different in emergency and internal wards from that in the NICU ward ( $p$-value $<0.05$ ).

Table 4. Mean and standard deviation of general health questionnaire (GHQ) subscales in different wards of the hospital

\begin{tabular}{cccccc}
\hline \multirow{2}{*}{ Ward } & Neonatal & NICU & Internal & Infectious & Emergency \\
\cline { 2 - 6 } & Mean \pm SD & Mean \pm SD & Mean \pm SD & Mean \pm SD & Mean \pm SD \\
\hline Somatic symptoms & $8.10 \pm 1.97$ & $9.10 \pm 2.23$ & $8.50 \pm 3.69$ & $9.67 \pm 2.55$ & $10.33 \pm 3.43$ \\
\hline Anxiety/insomnia & $9.20 \pm 3.29$ & $9.70 \pm 2.91$ & $9.80 \pm 3.19$ & $9.89 \pm 4.46$ & $10.67 \pm 3.91$ \\
\hline Social dysfunction & $7.80 \pm 1.14$ & $6.80 \pm 1.99$ & $9.80 \pm 3.29$ & $8.78 \pm 2.82$ & $9.44 \pm 3.25$ \\
\hline Severe depression & $5.10 \pm 3.14$ & $5.90 \pm 4.15$ & $7.10 \pm 7.19$ & $5.22 \pm 4.38$ & $9.33 \pm 6.58$ \\
\hline Total GHQ & $30.20 \pm 7.15$ & $31.50 \pm 6.35$ & $35.20 \pm 13.98$ & $33.56 \pm 10.99$ & $39.78 \pm 12.01$ \\
\hline
\end{tabular}

Table 5 illustrates the correlation between GHQ-28 subscales and the total scale in different wards of the hospital. According to the obtained data, there was a significant positive association between the GHQ-28 total scale and GHQ-28 subscales in all wards ( $p$-value $<0.01$ and $p$-value <0.05). In addition, Table 5 shows a significant positive correlation between anxiety/insomnia and somatic symptoms in the NICU (R2=0.758) and infectious $(R 2=0.854)$ wards ( $p$-value $<0.01)$. In the same vein, there was a positive significant correlation between social dysfunction and severe depression in the internal ward $(R 2=0.841)$ ( $p$-value $<0.01)$. 
Table 5. Inter-correlations between GHQ-28 subscales and the total scale in different wards of the hospital (bold numbers represent a significant correlation.)

\begin{tabular}{|c|c|c|c|c|c|}
\hline Ward & $\begin{array}{c}\text { General health } \\
\text { questionnaire subscales }\end{array}$ & $\begin{array}{l}\text { Somatic } \\
\text { symptoms }\end{array}$ & $\begin{array}{l}\text { Anxiety/ } \\
\text { insomnia }\end{array}$ & $\begin{array}{c}\text { Social } \\
\text { dysfunction }\end{array}$ & $\begin{array}{c}\text { Severe } \\
\text { depression }\end{array}$ \\
\hline \multirow{5}{*}{ Neonatal } & Somatic symptoms & - & & & \\
\hline & Anxiety/insomnia & 0.288 & - & & \\
\hline & Social dysfunction & $0.557^{*}$ & 0.279 & - & \\
\hline & Severe depression & 0.339 & 0.492 & 0.349 & - \\
\hline & Total GHQ & $0.646^{*}$ & $0.801^{\star *}$ & $0.594^{*}$ & $0.815^{* *}$ \\
\hline \multirow{5}{*}{ NICU } & Somatic symptoms & - & & & \\
\hline & Anxiety/insomnia & $0.758^{* *}$ & - & & \\
\hline & Social dysfunction & 0.355 & 0.257 & - & \\
\hline & Severe depression & -0.71 & -0.334 & -0.57 & - \\
\hline & Total GHQ & $0.764^{* *}$ & $0.587^{*}$ & $0.591^{*}$ & $0.611^{*}$ \\
\hline \multirow{5}{*}{ Internal } & Somatic symptoms & - & & & \\
\hline & Anxiety/insomnia & 0.368 & - & & \\
\hline & Social dysfunction & 0.284 & $0.662^{*}$ & - & \\
\hline & Severe depression & 0.170 & $0.675^{*}$ & $0.841^{* *}$ & - \\
\hline & Total GHQ & $0.563^{*}$ & $0.828^{* *}$ & $0.894^{* *}$ & $0.911^{\text {** }}$ \\
\hline \multirow{5}{*}{ Infectious } & Somatic symptoms & - & & & \\
\hline & Anxiety/insomnia & $0.854^{* *}$ & - & & \\
\hline & Social dysfunction & $0.580^{*}$ & $0.625^{*}$ & - & \\
\hline & Severe depression & 0.276 & 0.168 & 0.470 & - \\
\hline & Total GHQ & $0.837^{* *}$ & $0.826^{* *}$ & $0.824^{\star *}$ & $0.651^{*}$ \\
\hline \multirow{5}{*}{ Emergency } & Somatic symptoms & - & & & \\
\hline & Anxiety/insomnia & $0.654^{*}$ & - & & \\
\hline & Social dysfunction & $0.749^{*}$ & 0.270 & - & \\
\hline & Severe depression & 0.139 & 0.277 & 0.045 & - \\
\hline & Total GHQ & $0.7766^{* *}$ & 0.737 & $0.596^{*}$ & $0.690^{*}$ \\
\hline
\end{tabular}

Table 6 shows the mean and standard deviation of noise annoyance scales (NAS) in different wards of the hospital. As Fig. 1 shows, there were five ranges for the classification of annoyance. According to the obtained results and Fig. 1, the mean score of the noise annoyance scale was very high in four wards among the studied ones, including NICU, internal, infectious, and emergency wards; in addition, it was high in the neonatal ward. Furthermore, the highest and lowest mean of noise annoyance was found for the emergency (91.67) and neonatal (65.50) wards, respectively.

The results of the one-way ANOVA showed the mean score of noise annoyance was significantly different only between the infectious and neonatal wards ( $p<0.05, \mathrm{Cl} .95 \%$ : 1.94-35.95) as well as between the emergency and neonatal wards $(p<0.05$, Cl. 95\%: 9.16-43.17).

Table 6. Mean and standard deviation of the noise annoyance scale (NAS) in different wards of the hospital.

\begin{tabular}{cccccc}
\hline \multirow{2}{*}{ Ward } & Neonatal & NICU & Internal & Infectious & Emergency \\
\cline { 2 - 6 } & Mean \pm SD & Mean \pm SD & Mean \pm SD & Mean \pm SD & Mean \pm SD \\
\hline Noise annoyance & $65.50 \pm 30.68$ & $76.00 \pm 16.47$ & $81.50 \pm 16.34$ & $84.44 \pm 10.74$ & $91.67 \pm 5.59$ \\
\hline
\end{tabular}

\section{Discussion}

The present study was conducted to evaluate noise pollution and the association of the sound level and noise annoyance with general health among Iranian nurses at Tabriz Pediatric Hospital. According to the obtained results, the mean of the LAeq (dBA) in different wards of the studied hospital was higher than the levels suggested by the US-EPA, the WHO, the AAP, and the national standard. The highest LAeq was obtained for the emergency unit, which could have been due to the the highest rate of patient referrals and screaming patients at the early stages of treatment, as well the high number of patients' attendants. The results of the study by Bharathan et al (2014) showed that the highest noise level was related to the emergency room, so the human factor could be the main cause of noise pollution (20). Based on 
the study conducted by $\mathrm{H}$. Naderi et al (2017), most of the noise generated in these studies were related to talking and human behavior (21).

Krachman et al (2017) suggest that in order of controlling and reducing the noise generated at hospitals by people talking, a procedure should be designed to educate staff on the method of decreasing noise and informing them on its adverse effects on patients' health (21). Walderes Filus et al (2015) and Douglas Orellana et al $(2007)$ have reported similar results in their studies $(22,23)$.

According to the results of the present study, the highest sound level occurred on afternoon shifts in all wards except for the emergency ward, which could have been due to the changing of the shifts, nurses visiting patients, family members of visitors or patients talking, food being served, etc. These results are consistent with the conclusions of the studies by Galindo et al (2016), Lawson et al (2010), as well as Knutson and Konkani (2012)(2426).

The results of the statistical analysis showed that there was no significant difference among different shifts in the sound level in the emergency ward. This could have been due to the working procedure of this ward being different from that of other wards because the emergency care unit does not have a specific time for treatment activities, and clinical operations are performed on demand all day long. Khademi et al (2009) examined noise pollution in the intensive care units (ICUs) and emergency wards of Imam Reza Teaching Hospital, Mashhad, Iran, and identified no particular time pattern of noise variations due to the all-day nature of procedures in the emergency unit (27).

The highest and most fluctuating sound level among all wards, except for the emergency unit, occurred in the daytime from 10:00 a.m. to 05:00 p.m. The increase in the sound level changes in this period could have been due to activities, such as visiting and feeding, patients' visitors or family members talking, presence of social workers, examination of patients, and peak periods of office work, and the staff. The study by Galindo et al (2015) on the sound level in the ICUs of a public university hospital in Santa Marta (Colombia) showed that various activities, such as the changing of shifts, the visiting of patients, and the feeding of patients increased the sound level in ICUs (26).

According to the results of the present research, there was a significant positive association between the sound level and noise annoyance. Due to the high sound level in the emergency and internal wards, the above-mentioned association was significant in these wards. Hence, it could be asserted that some factors, such as work-related stress (since nurses suffer from a higher level of stress in these wards), being duty-bound to care for patients, feeling tired, and being busy could increase the sensitivity of individuals to noise annoyance. Nassiri (2014) found a association between the sound level and noise annoyance, which was not significant $(7,28)$. However, the results of the present research revealed that the sound level and noise annoyance were significantly correlated $(R 2=0.969, p<0.05)$. In line with the present study, the results of the studies by Schreckenberg et al (2010) and Aslak Fyhri et al (2010) revealed that the association between the sound level and noise annoyance was significant $(29,30)$. Morrison et al found out that high sound levels along with stress could increase annoyance among healthcare personnel (31).

According to Table 6, the highest mean score of the total GHQ was observed in the emergency ward $(39.78 \pm 12.01)$, which could be due to the staff's high median age, specific conditions of their work, and long daily working hours in this ward. Studies on the effects of work experience on nurses showed that the adverse effects of noise affected nurses with longer work experience. The results of the studies by Juang et al showed that old age, work experience, and daily working hours had a positive association with individuals' sensitivity to noise (16).

In this study, the investigation of the association between general health questionnaire subscales and the sound level in different hospital wards showed that the association among the sound level, GHQ-28 subscales, and the total scale was insignificantly positive. However, the association of anxiety/insomnia, social dysfunction, severe depression subscales, and general health with the sound level was significant only in the infectious ward $(p<0.05)$. These findings could have been due to the heavy workload assigned to a small number of nurses in the infectious ward (1 nurse per 2 patients). In addition, it could have been due to the large number of active beds in the infectious ward than in other wards (more than 40 active beds). The results of the study by Kinstler et al (2015) on the effects of noise on nurses employed in pediatric intensive care wards showed that although noise did not lead to stress, it had a significant correlation with the increase in the heart rate. These findings indicate that noise could be associated with adverse health outcomes among the nurses employed in pediatric intensive care wards (15). However, Nassiri et al (2014) and Kishikawa et al (2009) reported results different from our studies $(28,32)$. The reason that their 
findings were not similar to ours in the present study could be due to the low workload (the large number of nurses versus patients), satisfaction and compatibility among nurses with the work environment, their familiarity with working procedures at hospital, and their higher tolerance.

In the present study, the investigation of the association between general health questionnaire subscales and the noise annoyance scale in different hospital wards revealed that the association of noise annoyance with GHQ-28 subscales and the total scale was not significant, except in the following cases:

There was a significant positive association between the anxiety/insomnia subscale and the noise annoyance scale in the neonatal ward $(R 2=0.582)$. This result was consistent with the findings of a previous study that showed noise annoyance could exert a significant effect on the night's sleep, thereby leading to sleep problems (30). This situation could arise due to the noise caused by crying babies, devices equipped with sound alarms and infusion pumps, types of shift work, less sleep durations, and increased awakening levels. In addition, there was a significant negative association between the severe depression subscale and general health with the noise annoyance scale in the emergency ward $(R 2=-0.782$ and $R 2=-0.748$, respectively). According to the nurses, this situation could be due to the adaptability of nurses to the workplace, familiarity with working processes in the mentioned ward, and their higher level of forbearance, for the highest mean score of work experience was related to this ward. In fact, the major factor in noise annoyance could be individuals' attitude towards noise in the workplace as well as their knowledge and awareness.

Schreckeberg et al (2010) reported that the association of noise annoyance with physical health and mental health was insignificant (29). Along the same lines, Zamanian et al (2015) investigated the association between sound annoyance and general health in hospital staff and found out that the association of the noise annoyance scale with severe depression, somatic symptoms, and anxiety/insomnia subscales was insignificant (7). These results were consistent with the results of this study.

\section{Conclusion}

The level of noise in all study wards, especially in the emergency care ward, was above the Iranian occupational exposure limit (OEL), which could exert adverse health effects on healthcare workers in the study hospital. The results of noise level measurements in different wards of the study hospital suggested that hospital noise could have the potential for adversely affecting general health in staff members. Research on hospital noise and related health effects in other hospitals, in different seasons, and at different times are suggested. In addition, standard procedures and appropriate noise control strategies must be employed to reduce noise levels and noise exposure. Noise control strategies at hospital and reduced levels of noise could help provide an appropriate atmosphere in hospital wards, enhance patient comfort, and minimize adverse effects associated with noise exposure. In addition, noise reduction could result in reducing stress levels, promoting job performance in nurses, and improving patient care.

\section{Acknowledgement}

The authors would like to thank the staff at Tabriz Pediatric Hospital for helping conduct this research. There was no fund received from any organization to support this research financially.

Conflict of interest: None declared.

\section{References}

1. Shepherd D, Welch D, Dirks KN, Mathews R. Exploring the relationship between noise sensitivity, annoyance and health-related quality of life in a sample of adults exposed to environmental noise. Int $\mathrm{J}$ Environ Res Public Health 2010; 7(10):3579-94.

2. Leventhall HG. Low frequency noise and annoyance. Noise Health 2004; 6(23):59-72.

3. Kaur H., Rohlik GM, Nemergut ME, Tripathi S. Comparison of staff and family perceptions of causes of noise pollution in the Pediatric Intensive Care Unit and suggested intervention strategies. Noise Health 2016; 18(81):78-84.

4. Christensen M. What knowledge do ICU nurses have with regard to the effects of noise exposure in the Intensive Care Unit? Intensive Crit Care Nurs 2005; 21(4):199-207.

5. Freedman NS, Gazendam J, Levan L, Pack Al, Schwab RJ. Abnormal sleep/wake cycles and the effect of environmental noise on sleep disruption in the intensive care unit. $\mathrm{Am} \mathrm{J}$ Respir Crit Care Med 2001; 163(2):451-7.

6. Babisch W, Pershagen G, Selander J, Houthuijs $D$, Breugelmans $O$, Cadum E, et al. Noise annoyance -- a modifier of the association between noise level and cardiovascular health? Sci Total Environ 2013; 452-453:50-7.

7. Zamanian Z, Kouhnavard B, Maleki B, Ashrafi F, Ahmadvand L, Azad P. The relationship between sound annoyance and general health 
in hospital personnel in Shiraz in 2014-15. Iranian Journal of Ergonomics 2015; 3(2):14-21.

8. Ryherd, EE, Okcu S, Ackerman J, Zimring C, Waye KP. Noise pollution in hospitals: impacts on staff. Journal of Clinical Outcomes Management 2012; 19(11):491-500.

9. Ryherd EE, Waye KP, Ljungkvist L. Characterizing noise and perceived work environment in a neurological intensive care unit. J Acoust Soc Am 2008; 123(2):747-56.

10. Andrade KP, Oliveira LLAd, Souza RdP, Matos LMd. Noise level measurement and its effects on hospital employees based on complaint reports. Revista CEFAC 2016; 18(6).

11. Berglund B, Lindvall T, Schwela DH. Guidelines for community noise. Landon, United Kingdom: WHO- expert task force meeting held; 1999 April. 21p.

12. Darcy AE, Hancock LE, Ware EJ. A descriptive study of noise in the neonatal intensive care unit: ambient levels and perceptions of contributing factors. Adv Neonatal Care 2008; 8(5 Suppl):S16-26.

13. Rahimi Moghadam S, Laiegh Tizabi MN, Khanjani N, Emkani M, Taghavi Manesh V, Mohammadi AA, et al. Noise pollution and sleep disturbance among Neyshabur Hospital staff, Iran (2015). Journal of Occupational Health and Epidemiology 2018; 7(1):53-64.

14. Li SY, Wang TJ, Vivienne Wu SF, Liang SY, Tung $\mathrm{HH}$. Efficacy of controlling night-time noise and activities to improve patients' sleep quality in a surgical intensive care unit. J Clin Nurs 2011; 20(3-4):396-407.

15. Watson J, Kinstler A, Vidonish 3rd WP, Wagner M, Lin L, Davis KG, et al. Impact of Noise on Nurses in Pediatric Intensive Care Units. Am J Crit Care 2015; 24(5):377-84.

16. Juang DF, Lee $\mathrm{CH}$, Yang T, Chang MC. Noise pollution and its effects on medical care workers and patients in hospitals. International Journal of Environmental Science and Technology 2010; 7:705-16.

17. Goldberg DP, Hillier VF. A scaled version of the General Health Questionnaire. Psychol Med 1979; 9(1):139-45.

18. Kaczmarska A. Łuczak A. A study of annoyance caused by low-frequency noise during mental work. Int J Occup Saf Ergon 2007; 13(2):11725.

19. Sterling M. General Health Questionnaire-28 (GHQ-28). Journal of Physiotherapy 2011; 57(4):259.

20. Bharathan T, Glodan D, Ramesh A, Vardhini B,
Baccash E, Kiselev $P$, et al. What do patterns of noise in a teaching hospital and nursing home suggest? Noise Health 2007; 9(35):31-4.

21. Fasih-Ramandi $F$, Nadri $H$. Background noise in Iranian hospital intensive care units. Noise Control Eng J 2017; 65(1):14-21.

22. Filus W, de Lacerda ABM, Albizu E. Ambient Noise in Emergency Rooms and Its Health Hazards. Int Arch Otorhinolaryngol 2015; 19(3):205-9.

23. Orellana D, Busch-Vishniac IJ, West JE. Noise in the adult emergency department of Johns Hopkins Hospital. J Acoust Soc Am 2007; 121(4):1996-9.

24. Lawson N, Thompson K, Saunders G, Saiz J, Richardson J, Brown D, et al. Sound intensity and noise evaluation in a critical care unit. Am J Crit Care 2010; 19(6):e88-98.

25. Knutson AJ. Acceptable noise levels for neonates in the neonatal intensive care unit [PhD thesis]. Washington, United States: Washington University; 2013.

26. Garrido Galindo AP, Caicedo TC, Vélez-Pereira AM. Noise level in intensive care units of a public university hospital in Santa Marta (Colombia). Med Intensiva 2016; 40(7):403-10.

27. Khademi G, Roudi M, Farhat AS, Shahabian M. Noise pollution in intensive care units and emergency wards. Iran J Otorhinolaryngol 2011; 23(65):141-8.

28. Nassiri $P$, Heidari HR, Khadem M, Rahimifard $\mathrm{H}$, Rostami E. Assessment of Noise Annoyance and its Effects on Healthcare Staff Based on Sound Pressure Level and Annoyance Scale. International Journal of Occupational Hygiene 2014; 6(1):23-30.

29. Schreckenberg D, Griefahn B, Meis M. The associations between noise sensitivity, reported physical and mental health, perceived environmental quality, and noise annoyance. Noise Health 2010; 12(46):7-16.

30. Fyhri A, Aasvang GM. Noise, sleep and poor health: Modeling the relationship between road traffic noise and cardiovascular problems. Sci Total Environ 2010; 408(21):4935-42.

31. Morrison WE, Haas EC, Shaffner DH, Garrett ES, Fackler JC. Noise, stress, and annoyance in a pediatric intensive care unit. Criti Care Med 2003; 31(1):113-9.

32. Kishikawa $\mathrm{H}$, Matsui $\mathrm{T}$, Uchiyama I, Miyakawa M, Hiramatsu K, Stansfeld SA. Noise sensitivity and subjective health: questionnaire study conducted along trunk roads in Kusatsu, Japan. Noise Health 2009; 11(43):111-7. 